\title{
Diversité et évaluation participative des cultivars du manioc (Manihot esculenta Crantz) au Centre Bénin
}

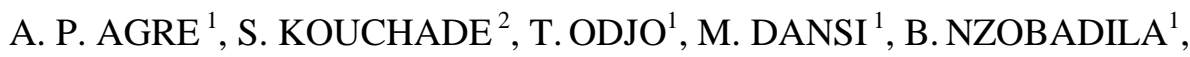 \\ P. ASSOGBA ${ }^{1}$, A. DANSI $^{1 *}$, A. AKOEGNINOU ${ }^{2}$ et A. SANNI ${ }^{3}$ \\ ${ }^{1}$ Laboratoire de Biotechnologies, Ressources Génétiques et Amélioration des Espèces Animales et Végétales \\ (BIORAVE), Faculté des Sciences et Techniques de Dassa, Université Polytechnique d'Abomey, \\ BP14 Dassa, Benin. \\ ${ }^{2}$ National Herbarium, Department of Botany and Plant Biology, Faculty of Sciences and Technology (FAST), \\ University of Abomey-Calavi (UAC), BP 526, Cotonou, Benin. \\ ${ }^{3}$ Laboratory of Biochemistry and Molecular Biology, Faculty of Sciences and Technology (FAST), \\ University of Abomey-Calavi (UAC), P.O. Box 526 Cotonou, Benin. \\ *Auteur correspondant, E-mail: adansi2001@gmail.com
}

\section{RESUME}

Le manioc est une plante alimentaire qui contribue fortement à la sécurité alimentaire au Bénin. Pour évaluer sa diversité variétale, les performances agronomiques, technologiques et culinaires de ses cultivars dans la région centrale du Bénin, 41 villages ont été prospectés. Sous réserve de synonymie, 107 cultivars de manioc ont été recensés dont 59 élites. L'indice de diversité de Shannon est de 3,78 et traduit une importante diversité variétale. Le nombre de cultivars recensés varie de 3 à 26 par village (10 en moyenne). Dans les villages où une perte de diversité variétale est notée, son taux a varié de 6,25 à $80 \%$ avec un taux moyen de 42,22\% par village. Les cultivars à produire sont choisis sur la base de 21 critères dont les plus importants sont la forte productivité $(16,37 \%$ de reponses), la qualité et le rendement en gari (15,52\% de reponses) et la précocité (13,27\% de reponses). Les contraintes de production ( 9 au total) perçues par les producteurs peuvent etre levées par l'utilisation des cultivars performants. L'évaluation participative a révélé l'existence de très peu de cultivars performants par rapport aux paramètres biotiques et abiotiques. La mise en place d'un programme d'amélioration et de création variétale est fortement recommandée pour la relance de la production du manioc au Bénin.

(C) 2015 International Formulae Group. All rights reserved.

Mots clés : Bénin, critère de préférence, cultivar élite, diversité variétale, évaluation participative, manioc.

\section{INTRODUCTION}

Le manioc (Manihot esculenta Crantz, Euphorbiaceae) est une plante alimentaire tropicale cultivée pour ses racines riches en hydrate de carbone et pour ses feuilles riches en vitamines, en sels minéraux et en protéines (Esuma et al.,
2012 ; da Costa et al., 2013). Très énergétique (350 kilocalories pour 100 grammes de matière sèche), il est utilisé comme aliments de base par plus de 500 millions de personnes à travers le monde (Kumba, 2012). Son amidon a de nombreux usages dans les domaines industriels et pharmaceutiques. 
Sa production annuelle mondiale est estimée à environ 250 million de tonne avec $52 \%$ pour l'Afrique (FAO, 2013). En Afrique, la culture du manioc occupe plus de $6 \%$ des espaces emblavés et concerne $70 \%$ des actifs agricoles (MAEP, 2013). Adaptée à plusieurs conditions écologiques et aux zones marginales, la culture du manioc ne nécessite pas une grande gestion comparativement aux autres cultures (Carinne et al., 2011 ; Kombo et al., 2012 ; Turyagyenda et al., 2013). Dans la sous-région (Afrique Centrale et de l'Ouest) le manioc est la principale racine et tubercule la plus consommée et la plus exploitée (Guerrero et al., 2012).

Au Bénin, les racines du manioc sont consommées sous plusieurs formes (cuite, crûes ou transformées en cossette, en gari, en tapioca, lafun, etc.). Les feuilles sont également consommées sous forme de légumes et constituent un complément azoté. Par ailleurs, certains cultivars qualifiés de toxique ne sont consommés qu'après une série de transformation. Culture de subsistance à l'origine, le manioc tend à devenir une culture contribuant à la réduction de la pauvreté par la commercialisation de ses nombreuses dérivées (Hongbété et al., 2011). Malgré son importance, la production du manioc est confrontée à de nombreuses contraintes (insuffisance de cultivars performants, forte sensibilité des cultivars locaux aux maladies et ravageurs, pertes post-récoltes très élevées, effets des changements climatiques, etc.) qui rendent difficile sa culture (MAEP, 2013). Au Benin, les travaux de recherche effectués sur le manioc ont porté essentiellement sur la production, les maladies et ravageurs (Onzo et al., 2005), la transformation post-récolte (Hongbetè et al., 2011), la commercialisation (Chiara et Serpagli 2009) et l'influence des hormones sur la culture in vitro de quelques cultivars (Cacaï et al., 2013). Les aspects liés aux ressources génétiques devant servir de base pour la création variétale ont été négligés (Agre et al., 2015). La diversité variétale, les performances des cultivars et les critères paysans de préférence restent encore inconnus. Nous présentons dans le présent article les résultats d'une investigation ethnobotanique qui visait à:

- Situer l'insuffisance de cultivars performants parmi les contraintes liées à la production du manioc perçues par les producteurs au centre Bénin;

Evaluer la diversité variétale du manioc et son évolution au centre Bénin ;

- Evaluer de façon participative les caractéristiques agronomiques, technologiques et culinaires des cultivars existants;

- Identifier les critères paysans de préférence variétale et comprendre leur variation à travers les zones agroécologiques et ethniques pour les besoins de la sélection et de la vulgarisation. 1

\section{MATERIEL ET METHODES \\ Présentation de la zone d'étude}

L'étude s'est déroulée de mai à juin 2013 dans sept communes différentes (Bantè, Dassa, Djidja, Glazoué, Ouèssè, Savalou et Savè) du centre du Bénin. La zone d'étude est majoritairement occupée par les groupes sociaux linguistiques Idaasha (Dassa, Glazoué), Mahi/Fon (Savalou/Djidja), Tchabè (Savè et Ouèssè) et Ifè (Bantè). Le climat est subéquatorial humide avec une pluviométrie annuelle allant de 1000 à $1100 \mathrm{~mm}$, deux saisons pluvieuses et deux saisons sèches (Adomou et al., 2006). La température moyenne varie de 24 à $29^{\circ} \mathrm{C}$. Les sols sont en majorité ferrugineux et les cultures pratiquées peuvent être regroupées en cinq catégories : les céréales (maïs, riz, sorgho), les légumineuses (niébé, voandzou), les racines et tubercules (manioc, igname, patate douce), les cultures maraîchères (piment, tomate) et les cultures de rente (coton et cajou). Les villages prospectés ont été choisis à travers toute la zone en prenant en compte l'accessibilité et de la nécessité d'une bonne couverture. Les villages prospectés (41 au total) sont regroupés dans le Tableau 1 et leurs localisations géographiques sont indiquées sur la Figure 1 


\section{Méthodologie et données collectées}

Dans chaque village, les données ont été collectées en utilisant les méthodes de la recherche participative (enquêtes de groupe et visites des champs) d'après Orobiyi et al. (2013). Par village, un groupe de 20 à 30 producteurs de manioc des deux sexes et de différents âges ont été identifiés et réunis avec l'aide du chef du village ou de l'association des producteurs. Les contraintes biologiques de la production du manioc ont été listées par les producteurs en groupe et hiérarchisées par la méthode d'identification et d'élimination progressive de la contrainte la plus importante définie par Dansi et al. (2013). Dans chaque village, l'inventaire variétal a été fait de manière participative d'après Kombo et al. (2012). La distribution et l'étendue des cultivars listés ont été appréciées par la méthode participative d'analyse des 4 carrés ou "Four Square Analysis" selon Gbaguidi et al. (2013). Cette approche permet de classer en quatre catégories (cultivars produits par beaucoup de ménages sur de grandes superficies; cultivars produits par beaucoup de ménages sur de petites superficies; cultivars produits par peu de ménages sur de grandes superficies et cultivars produits par peu de ménages sur de petites superficies) les cultivars produits à l'échelle d'un village. Ensuite les discussions ont été menées sur chaque cultivars avec pour objectif la compréhension de leur statut (position dans les cadrans). Par conséquent, les raisons qui justifient la culture de chaque variété par peu ou beaucoup de ménages et sur de petites ou grandes surfaces ont été relevées (Gbaguidi et al., 2013). La méthode d'analyse des quatre carrés permet l'identification des cultivars élites (ceux cultivées sur de grandes superficies et par beaucoup de ménages dans au moins un des villages prospectés) et l'évaluation du taux de perte de diversité variétale à partir des cultivars produits par peu de ménages et sur de petites superficies. Dans chaque village prospecté et en groupe, chaque cultivar a été évalué pour un ensemble de variables d'ordre agronomiques, technologiques et culinaires.
Deux méthodes permettent d'identifier et d'hiérarchiser les critères paysans de préférence variétale: enquête individuelle avec la méthode de matrice de comparaison (Dansi et al., 2010) et enquête de groupe (Gbaguidi et al., 2013). Dans le cas de cette étude, la méthode de groupe est celle utilisée. Dans chaque village, les producteurs ont été amenés à lister en groupe les caractéristiques que doit avoir un cultivar du manioc pour être largement adopté dans le contexte de leur village. Ces critères de préférence ont été hiérarchisés suivant leurs importances $(\%$ du nombre de villages dans lequel chaque critère est cité).

\section{Analyses statistiques des données}

Les données obtenues au cours des enquêtes ont été analysées par la statistique descriptive (moyenne, pourcentage, variance, etc.) et les résultats ont été présentés sous forme de Tableaux, graphes et Figures. Les contraintes identifiées dans chaque village et classées en groupe par degré d'importance ont été hiérarchisées d'après Orobiyi et al. (2013) au niveau de la zone d'étude sur la base de la moyenne des trois paramètres suivants : nombre de villages dans lesquels la contrainte est citée (NTV); Nombre de villages dans lesquels la contrainte est perçue comme principale $(\mathrm{CP})$; nombre de villages dans lesquels la contrainte est majeure ou classée entre les cinq premières (CM). Pour chacun de ces paramètres, une valeur élevée indique une importance pour la contrainte. Ainsi, l'importance d'une contrainte est déterminée par la formule suivante $\mathrm{IMC}=(\mathrm{NTV}+\mathrm{CP}+$ CM)/3.

Le taux de perte ou de menace des cultivars (TPC) à l'échelle du village est calculé selon Gbaguidi et al. (2013) d'après la formule $\mathrm{TPC}=[(\mathrm{n}-\mathrm{k}) / \mathrm{N}] \times 100$ avec $\mathrm{n}$ : nombre de cultivars en disparition, $\mathrm{k}$ : nombre de cultivars nouvellement introduits et $\mathrm{N}$ : le nombre total de cultivars recensés dans le village. L'Indice de diversité de Shannon $(\mathrm{H})$ qui permet d'évaluer l'importance de la diversité est calculé pour la zone d'étude selon Shannon and Weaver (1948). 
Afin d'analyser le degré de ressemblance entre les différents cultivars élites de cette zone, ceux-ci ont été considérés comme des individus et les paramètres $(11 \mathrm{au}$ total) d'évaluation agronomique (précocité, productivité, conservation post-maturité sous terre, goût, teneur en fibre, teneur en amidon, rendement et qualité du gari, qualité du tapioca, qualité de la pâte de cossettes, résistance des cossettes aux insectes) les plus utilisés par les producteurs comme des variables et codé 1 lorsque performant ou 0 dans le cas contraire. Un tableau disjonctif complet est alors construit et utilisé pour produire une matrice de similarité et un dendrogramme avec le logiciel Statistica version 7.1.

\section{RESULTATS}

Données sociodémographiques des enquêtés, importance et contraintes de la culture du manioc

Les producteurs enquêtés dans la zone d'étude sont composés d'hommes $(81,33 \%)$ et de femmes $(19,67 \%)$ âgés de 18 à 75 ans. L'âge moyen des producteurs est de 46 ans. Ils ont en moyenne 25 ans d'expérience dans la culture du manioc et sont en majorité (72\% de producteurs) analphabètes. La taille des ménages des enquêtés varie de 1 à 40 personnes avec une moyenne de 19 personnes par ménage. La majorité $(80 \%)$ des producteurs enquêtés cultive le manioc sur des superficies variant entre 0,02 ha à 1,5 ha. Seuls $4,67 \%$ de ces producteurs cultivent le manioc sur des superficies relativement grandes (3 à 6 ha).

Dans la zone d'étude, le manioc occupe une place importante parmi les cultures vivrières. Il est classé par $44 \%$ des producteurs soit en première position $(15,33 \%$ de producteurs) ou en deuxième position (28,67\% de producteurs). Parmi les raisons qui motivent la culture du manioc figure l'autoconsommation $\quad(47 \%$ de réponses), la transformation en cossettes (21\% de réponses), et en gari (20\% des réponses) pour la commercialisation sur les marchés locaux. La vente de racines fraîches de manioc est pratiquée par $6 \%$ des producteurs enquêtés.

Neuf (9) contraintes liées à la production du manioc ont été identifiées et hiérarchisées dans la zone d'étude (Tableau 2). Parmi celles-ci, les plus importantes sont : l'insuffisance des cultivars performants, les variabilités climatiques (qui se traduisent soit par une insuffisance ou un arrêt précoce des pluies), les maladies et les ravageurs, la pauvreté des sols, les pourritures racinaires et la baisse de productivité au niveau de certains cultivars.

\section{Diversité variétale du manioc au centre Bénin}

Dans la zone d'étude, la diversité des cultivars varie de 3 à 26 par village avec une moyenne de 10 cultivars par village (Tableau 3). Sous réserve de synonymies, 107 différents cultivars de manioc ont été recensés à travers les 41 villages prospectés. La plus forte diversité (26 cultivars) a été observée à Assaba (Bantè) et la plus faible diversité (3 cultivars) a été enregistrée à Gossoé dans la commune de Dassa (Tableau 3). La commune de Bantè a présenté la plus forte diversité avec une moyenne de 15 cultivars par village et la commune de Dassa a présenté la plus faible diversité avec huit (8) cultivars en moyenne par village (Tableau 4). Toutefois on note une variation du nombre de cultivars par village au sein de la même commune (Tableau 4). L'indice de diversité de Shannon (H') calculé est de 3,78 et indique une forte diversité variétale dans la zone d'étude.

Les cultivars recensés dans la zone d'étude ont un cycle allant de 2 à 24 mois. Sous réserve de synonymie, les cultivars ayant un cycle allant de 10 à 12 mois sont les plus nombreux et représentent 30,84\%. Les cultivars dont les cycles sont compris entre 12 et 18 mois et ceux de 6 à 8 mois représentent respectivement $22,42 \%$ et $14,95 \%$ (Figure 2). Un cultivar extra précoce de deux mois localement appelé Kpaki olotchu médji est aussi signalé. Il est cependant généralement récolté à six mois pour une maturité et une productivité plus avancée. 
L'analyse de la distribution et de l'étendue des cultivars recensés (Tableau 3), montre qu'en moyenne trois (3) cultivars de manioc sont produits par beaucoup de ménages et sur de grandes superficies. Ces cultivars (Idilèrou, Odohoungbo, Monlèkangan, Okôyawo, etc.) sont ceux qui ont, pour les producteurs, les meilleures performances agronomiques, culinaires et technologiques telle que forte productivité, bonne conservation post-maturité sous terre, bonne productivité en gari de qualité et bonne qualité des cossettes. Ils sont considérés comme des cultivars élites. En moyenne, deux (2) cultivars sont cultivés par beaucoup de ménages sur de petites superficies. Ces cultivars (Malègbra, Olôbèkpè, etc.) présentent généralement de bonnes caractéristiques culinaires mais ont certaines faiblesses comme la mauvaise conservation post-maturité sous terre et une faible productivité. Les cultivars produits par peu de ménages et sur de grandes superficies (Moumidélé, Tchabalou, etc.) sont ceux qui adorent des sols particuliers (non disponibles chez tous les producteurs) ou dont les semences sont difficiles à trouver. Ils sont en moyenne un (01) par village (Tableau 3). Quatre (4) cultivars en moyenne sont cultivés par peu de ménages et sur de petites superficies (Tableau 3). Selon les producteurs, ces cultivars (Agbari-èfun, Agôkpa, Assinanssan, Maboudé, etc.) présentent de nombreuses faiblesses comme la faible productivité, la sensibilité à l'excès d'humidité du sol, une mauvaise qualité gari (Farine de manioc) et du tapioca (amidon du manioc) et la présence de nombreuses fibres dans les racines.

Dans les villages où des cultivars en disparition ont été notés (Tableau 3), le taux de perte des cultivars varie de $6,25 \%$ (village Akatakou) à $80 \%$ (village Djaloukou) avec un taux moyen de 42,22\%. Dans les villages Agao, Agramidjodji, Akomiya, Gobé, Gossoé et Okémere aucune variété en disparition n'a été signalée.
Les cultivars recensés ont différentes distributions et étendues. Le cultivar Idilèrou cultivé à Okémere (Dassa), Djagbalo (Bantè), Gbédé (Ouessè) et Gbéré (Savè) par beaucoup de ménages et sur de grandes superficies est par contre cultivé à Akomiya (Glazoué), Akongbéré (Savè) et Sowé (Glazoué) par peu de ménages et sur de petites superficies et à Ibiyem et Oke-owo par peu de ménages et sur de grandes superficies (Tableau 5). Le cultivar Odohoungbo a une large distribution et est présent dans trente-six (36) des 41 villages prospectés où il se retrouve d'ailleurs toujours présent dans beaucoup de ménages et sur de grandes superficies (Tableau 5). A l'opposé, certains cultivars comme Israèl, Kpassa, Lèlibo, Olowo-oké ne se retrouvent que dans un seul village (Tableau 5).

Les causes de la perte de diversité variétale (Tableau 6) sont multiples et peuvent être regroupées dont les raisons agronomiques ( $89,80 \%$ de réponses) et les raisons culinaires et technologiques (10,20\% de réponses). Parmi les raisons agronomiques, les plus importantes sont la sensibilité à la sécheresse et aux fortes fluctuations des pluies $(33,33 \%$ de réponses), l'introduction de nouveaux cultivars surtout à partir des régions voisines (25,93\% de réponses) et la forte susceptibilité aux maladies virales (Mosaïque) entraînant une baisse régulière et drastique de la productivité $(12,97 \%$ de réponses). La toxicité des feuilles et des racines (5,60\% de réponses) et la mauvaise qualité du gari $(4,60 \%)$ sont les principales raisons culinaires et technologiques d'abandon des cultivars dans la zone d'étude (Tableau 6).

\section{Variétés performantes de manioc du centre Bénin}

A travers toute la zone prospectée et sous réserve de synonymies, 59 cultivars élites (cultivés par beaucoup de ménages et sur de grandes superficies dans au moins un des villages) ont été identifiés (Tableau 7). En se basant sur onze 11 variables agronomiques, culinaires et technologiques clés que les 
producteurs utilisent le plus souvent pour décrire leurs cultivars en termes de performance, les 59 cultivars élites recensés ont été regroupés en 25 Unités (U1 à U25 ; Tableau 7 ; Figure 4) et 5 différents groupes (G1 à G5 ; Figure 4):

- G1 est formé de 8 différentes unités (U1, U2, U3, U4, U5 U6, U9 et U10) et de 16 cultivars. Il regroupe des cultivars à forte productivité, caractérisés aussi par une bonne conservation post-maturité sous terre, un bon goût, un bon rendement en gari de bonne qualité, un fort taux d'amidon et une bonne qualité de tapioca.

G2 regroupe 6 unités $(7,11,12,13$, 14 et 15) caractérisées tous par une mauvaise conservation post- maturité sous terre, une faible teneur en fibres. Dans ce groupe on retrouve les cultivars donnant un gari et tapioca de bonne qualité (blanc et bon arome) et donnant de bonnes cossettes résistantes aux insectes de stockage (Tableau 7).

- G3 est constitué de 4 unités $(16,17$, 18 et 24) caractérisées par des cultivars de manioc à goût amer offrant cependant un bon rendement en gari. Ce sont aussi des cultivars ayant une forte teneur en amidon et de tapioca de bonne qualité. Il s'agit aussi des cultivars dont les cossettes sont bonnes et résistantes aux insectes de stockage.

- G4 est constitué de 9 unités (Figure 4) et de 18 cultivars (Tableau 7). C'est un groupe constitué de cultivars productifs mais ayant une mauvaise conservation postmaturité sous terre. Ils donnent cependant du gari de bonne qualité, des cossettes de bonne qualité et résistantes aux insectes de stockage et une bonne qualité de pâte de cossette

- G5 combine 3 unités avec cinq cultivars (Figure 4; Tableau 7). Ce groupe rassemble des cultivars à forte productivité mais avec une mauvaise conservation post maturité sous terre (transformation des racines en fibres ou pourriture en cas de retard de récolte) et des cossettes très attaquées par les insectes de stockage.
L'évaluation agronomique, culinaire et technologies participative des 107 cultivars identifiés dans la zone d'étude sous réserve de synonymie a révélé l'existence de quelques cultivars performants par paramètre d'évaluation (Figure 3). Beaucoup de cultivars performants existent pour les paramètres culinaires et technologiques mais certains paramètres clés (tolérance à l'excès d'humidité du sol, tolérance aux mauvaises herbes, conservation post-maturité sous terre, tolérance à la sécheresse, tolérance aux maladies virales, tolérance aux sols pauvres, productivité, précocité) sont très peu (moins de $25 \%$ des cultivars recensés) ou peu (moins de $50 \%$ des cultivars recensés) fournis (Figure 3).

\section{Critères paysans de préférence ou de sélection variétale}

Vingt et un (21) critères de préférence dont 01 économique (forte valeur marchande), 9 culinaires et technologiques et 11 agronomiques ont été identifiés à travers les villages (Tableau 8). Parmi ceux-ci, la forte productivité, la précocité, la bonne conservation post-maturité sous terre, la productivité et la qualité du gari, l'aptitude à donner du bon pilé, la qualité de la racine bouillie (friabilité), l'aptitude à faire de bonnes cossettes et la teneur en amidon sont les importants (Tableau 8). Bien que l'importance des critères soit variable d'une zone ethnique à une autre, la tendance générale est la même à travers toutes les zones ethniques considérées à quelques exceptions près (Tableau 8). Outre les critères d'importance, la tolérance à la sècheresse préoccupe particulièrement les Idaasha en même temps que la qualité de la racine bouillie, la teneur en amidon et la possibilité de consommation des feuilles sous forme de légume. La résistance des cossettes aux insectes de stockage reste le trait spécifique visé par les Tchabè. Les nago Fè ont insisté sur la qualité de la racine bouillie et la possibilité d'usages multiples. 


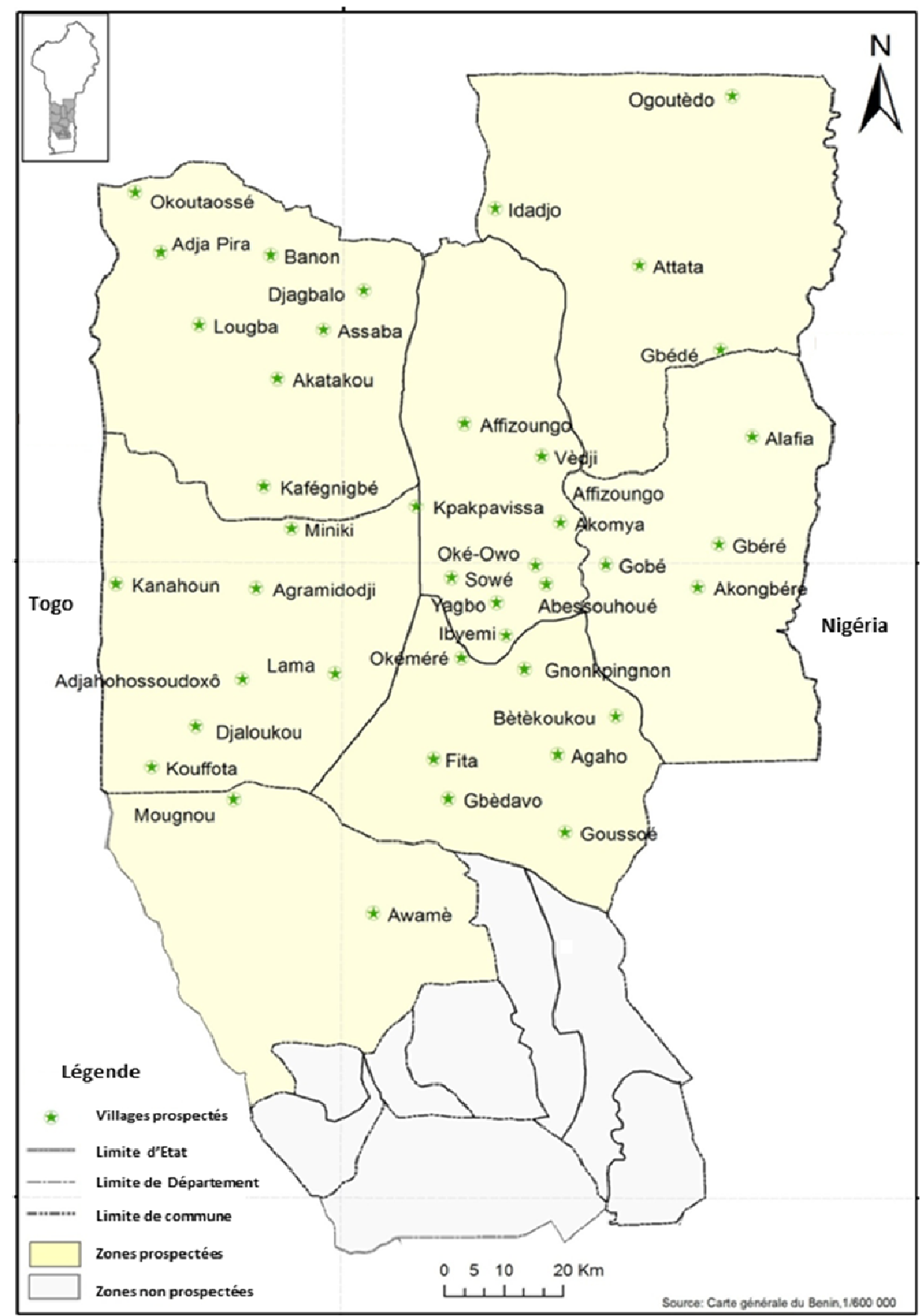

Figure 1 : Carte du centre Bénin montrant la localisation géographique des villages enquêtés. 


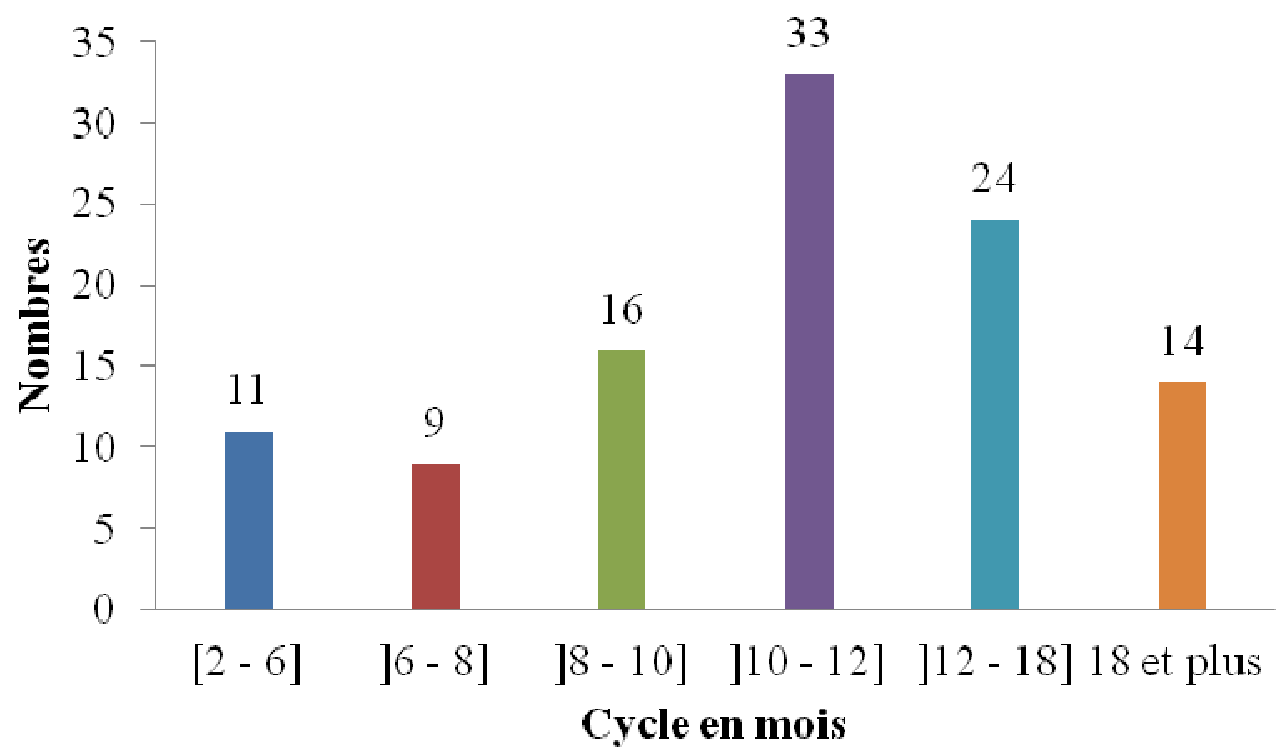

Figure 2 : Cycle des cultivars de manioc recensés au centre Bénin.

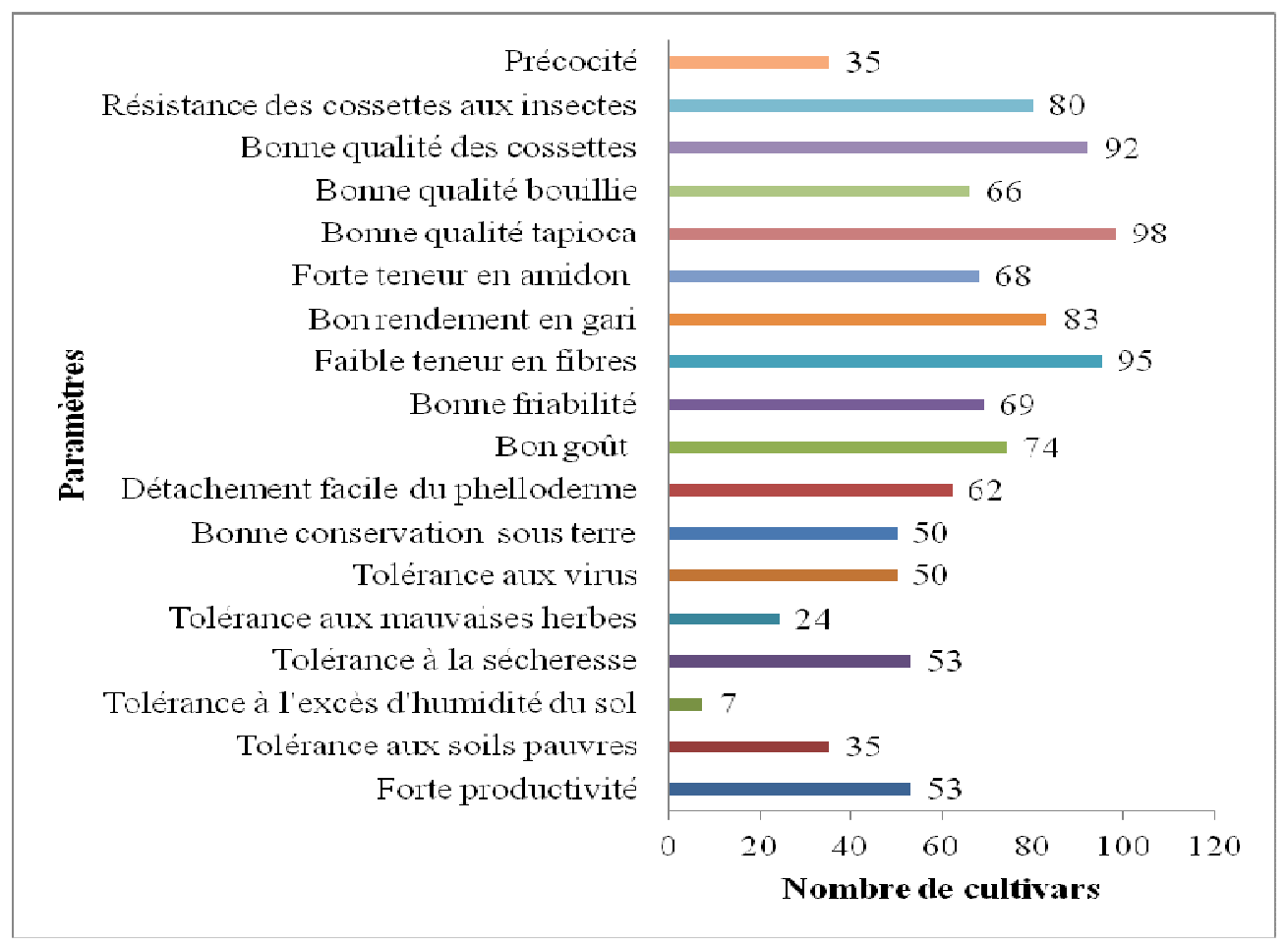

Figure 3 : Nombre de cultivars performants pour chaque paramètre évalué. 
A. P AGRE et al. /Int. J. Biol. Chem. Sci. 9(1): 388-408, 2015

Tableau 1 : Liste des villages prospectés dans le département des Collines.

\begin{tabular}{|c|c|c|c|}
\hline $\mathbf{N}^{\mathbf{0}}$ & Villages & District & Ethnie \\
\hline 1 & Abessouhoué & Glazoué & Fon \\
\hline 2 & Adja Pira & Bantè & Ifè \\
\hline 3 & Adjahohossoudoxô & Savalou & Mahi \\
\hline 4 & Affizoungo & Glazoué & Mahi \\
\hline 5 & Agaho & Dassa & Idaasha \\
\hline 6 & Agramidodji & Savalou & Mahi \\
\hline 7 & Akatakou & Bantè & Ifè \\
\hline 8 & Akomya & Glazoué & Idaasha \\
\hline 9 & Akongbéré & Savè & Tchabè \\
\hline 10 & Alafia & Savè & Tchabè \\
\hline 11 & Assaba & Bantè & Ifè \\
\hline 12 & Attata & Ouessè & Tchabè \\
\hline 13 & Awamè & Djidja & Fon \\
\hline 14 & Banon & Bantè & Ifè \\
\hline 15 & Bètèkoukou & Dassa & Idaasha \\
\hline 16 & Djagbalo & Bantè & Ifè \\
\hline 17 & Djaloukou & Savalou & Ifè \\
\hline 18 & Fita & Dassa & Fon \\
\hline 19 & Gbèdavo & Dassa & Fon \\
\hline 20 & Gbédé & Ouessè & Tchabè \\
\hline 21 & Gbéré & Savè & Tchabè \\
\hline 22 & Gnonkpingnon & Dassa & Mahi \\
\hline 23 & Gobé & Savè & Idaasha \\
\hline 24 & Goussoé & Dassa & Idaasha \\
\hline 25 & Ibiyém & Glazoué & Idaasha \\
\hline 26 & Idadjo & Ouessè & Tchabè \\
\hline 27 & Kafégnigbé & Bantè & Ifè \\
\hline 28 & Kanahoun & Savalou & Ifè \\
\hline 29 & Kouffota & Savalou & Mahi \\
\hline 30 & Kpakpavissa & Savalou & Mahi \\
\hline 31 & Lama & Savalou & Mahi \\
\hline 32 & Lougba & Bantè & Ifè \\
\hline 33 & Miniki & Savalou & Ifè \\
\hline 34 & Mougnou & Djidja & Fon \\
\hline 35 & Ogoutèdo & Ouessè & Tchabè \\
\hline 36 & Okéméré & Dassa & Idaasha \\
\hline 37 & Oké-owo & Glazoué & Idaasha \\
\hline 38 & Okouta-Ossè & Bantè & Ifè \\
\hline 39 & Sowé & Glazoué & Idaasha \\
\hline 40 & Vèdji & Dassa & Mahi \\
\hline 41 & Yagbo & Glazoué & Idaasha \\
\hline
\end{tabular}


Ward method

Eucludean distance

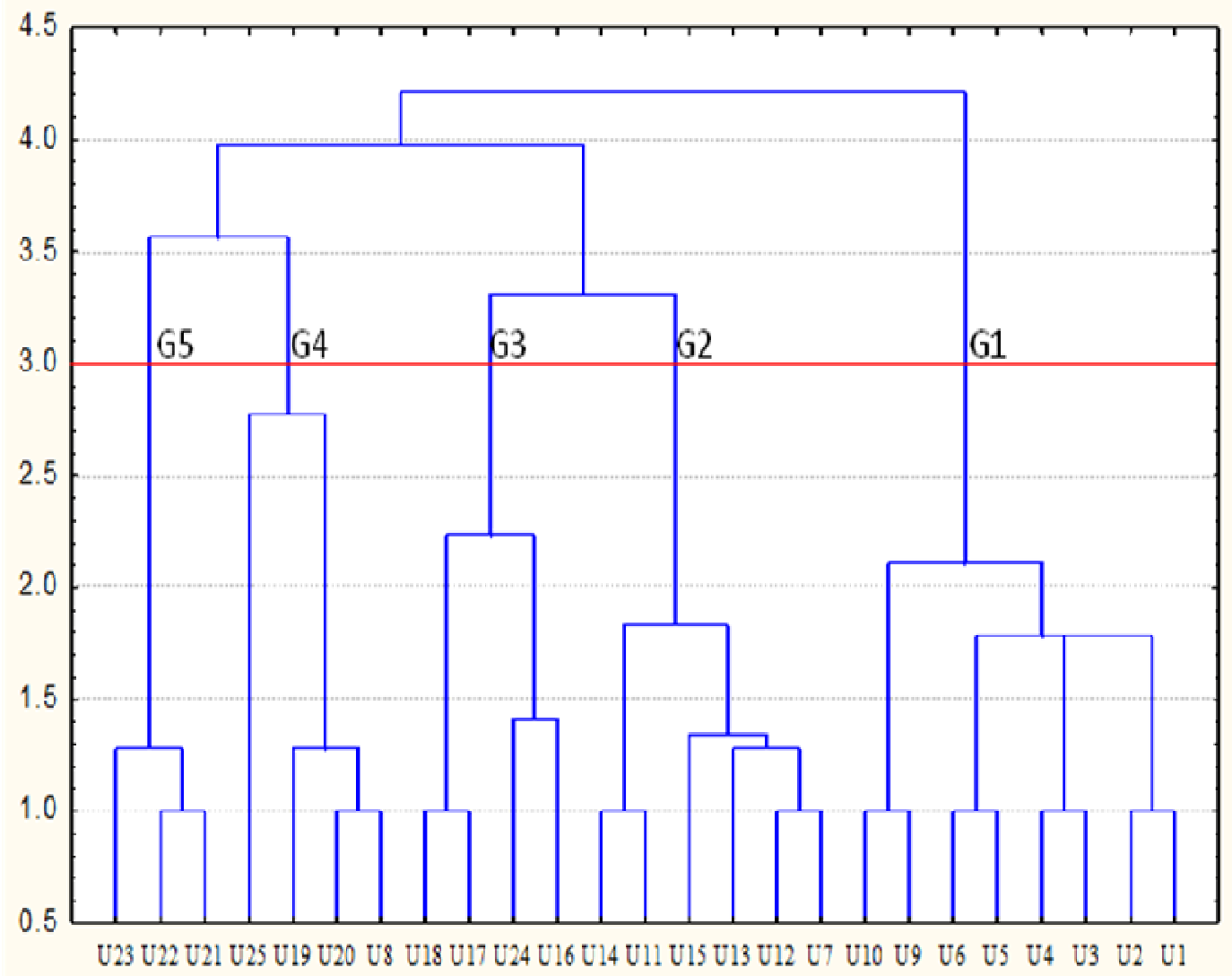

Figure 4 : Dendrogramme montrant les similarités entre les différentes unités.

Tableau 2: Contraintes liées à la production du manioc au centre du Bénin.

\begin{tabular}{lccccc}
\hline \multirow{2}{*}{ Contraintes } & \multicolumn{3}{c}{ Nombre de villages } & \multirow{2}{*}{ Moyenne } & \multirow{2}{*}{ Rang } \\
\cline { 2 - 4 } & NTV & CP & CM & & \\
\hline Insuffisance des cultivars performants & 37 & 15 & 20 & 24 & 1 \\
Rareté et insuffisance des pluies & 35 & 5 & 30 & 23,33 & 2 \\
Maladies et ravageurs & 36 & 5 & 15 & 18,66 & 3 \\
Pauvreté des sols & 29 & 10 & 5 & 14,66 & 4 \\
Pourritures racinaires & 20 & 8 & 13 & 13,66 & 5 \\
Baisse de productivité & 25 & 4 & 11 & 13,33 & 6 \\
Insuffisance de cultivars précoces & 15 & 5 & 7 & 9 & 7 \\
Sensibilité des cultivars aux mauvaises herbes & 10 & 0 & 5 & 5 & 8 \\
Mauvaise conservation des cossettes & 11 & 1 & 3 & 5 & 9 \\
\hline
\end{tabular}

NTV : nombre total de villages où la contrainte est citée, $\mathrm{CP}:$ nombre de villages où la contrainte est principale (la plus importante), $\mathrm{CM}$ : nombre de villages où la contrainte est majeure c'est-à-dire parmi les cinq premières. 
Tableau 3 : Diversité, distribution, étendue et taux de perte des cultivars de manioc par village.

\begin{tabular}{|c|c|c|c|c|c|c|c|c|c|}
\hline \multirow{2}{*}{$\mathbf{N}^{\mathbf{0}}$} & \multirow{2}{*}{ Village } & \multirow{2}{*}{ NTC } & \multicolumn{4}{|c|}{ Distribution et étendue } & \multirow{2}{*}{ CNI } & \multirow{2}{*}{ NCD } & \multirow{2}{*}{ TPC $(\%)$} \\
\hline & & & $\mathbf{M}+\mathbf{S}+$ & $\mathbf{M}+\mathbf{S}-$ & M-S+ & M-S- & & & \\
\hline 1 & Abessouhoue & 9 & 5 & 2 & 1 & 1 & 0 & 1 & 11,11 \\
\hline 2 & Adja Pira & 11 & 2 & 5 & 0 & 4 & 3 & 1 & 9,09 \\
\hline 3 & Adjahossoudoxô & 5 & 2 & 0 & 0 & 3 & 0 & 3 & 60 \\
\hline 4 & Affizoungo & 9 & 3 & 1 & 1 & 4 & 0 & 4 & 44,44 \\
\hline 5 & Agao & 8 & 5 & 1 & 1 & 1 & 1 & 0 & 0 \\
\hline 6 & Agramidodji & 12 & 7 & 0 & 0 & 6 & 6 & 0 & 0 \\
\hline 7 & Akatakou & 16 & 4 & 4 & 2 & 6 & 5 & 1 & 6,25 \\
\hline 8 & Akomiya & 8 & 5 & 1 & 1 & 1 & 1 & 0 & 0 \\
\hline 9 & Akongbère & 11 & 1 & 3 & 3 & 4 & 1 & 3 & 27,27 \\
\hline 10 & Alafia & 10 & 2 & 1 & 0 & 7 & 3 & 4 & 40 \\
\hline 11 & Assaba & 26 & 7 & 3 & 4 & 12 & 6 & 6 & 23,08 \\
\hline 12 & Attata & 8 & 2 & 4 & 0 & 2 & 1 & 1 & 12,50 \\
\hline 13 & Awamè & 8 & 0 & 1 & 0 & 7 & 1 & 6 & 75 \\
\hline 14 & Banon & 17 & 5 & 4 & 2 & 6 & 1 & 5 & 29,41 \\
\hline 15 & Bètècoucou & 9 & 5 & 1 & 1 & 2 & 0 & 2 & 22,22 \\
\hline 16 & Djagbalo & 11 & 4 & 2 & 1 & 4 & 1 & 3 & 27,27 \\
\hline 17 & Djaloukou & 5 & 1 & 0 & 0 & 4 & 0 & 4 & 80 \\
\hline 18 & Fita & 11 & 2 & 3 & 1 & 5 & 2 & 3 & 27,27 \\
\hline 19 & Gbedavo & 10 & 6 & 0 & 0 & 4 & 1 & 3 & 30 \\
\hline 20 & Gbédé & 13 & 3 & 4 & 0 & 6 & 2 & 4 & 30,77 \\
\hline 21 & Gbéré & 10 & 5 & 2 & 0 & 3 & 2 & 1 & 10 \\
\hline 22 & Gnonkpingnon & 8 & 3 & 1 & 2 & 2 & 0 & 2 & 25 \\
\hline 23 & Gobé & 5 & 1 & 3 & 1 & 0 & 0 & 0 & 0 \\
\hline 24 & Gossoe & 3 & 2 & 1 & 0 & 0 & 0 & 0 & 0 \\
\hline 25 & Ibiyem & 9 & 2 & 0 & 6 & 1 & 0 & 1 & 11,11 \\
\hline 26 & Idadjo & 9 & 6 & 1 & 0 & 2 & 1 & 1 & 11,11 \\
\hline 27 & Kafégnigbé & 12 & 3 & 2 & 1 & 6 & 2 & 4 & 33,33 \\
\hline 28 & Kanahoun & 13 & 2 & 3 & 0 & 8 & 2 & 6 & 46,15 \\
\hline 29 & Kouffota & 12 & 2 & 2 & 0 & 8 & 0 & 8 & 66,67 \\
\hline 30 & Kpakpavissa & 7 & 1 & 0 & 0 & 6 & 1 & 5 & 71,43 \\
\hline 31 & Lama & 13 & 4 & 4 & 0 & 4 & 0 & 4 & 30,77 \\
\hline 32 & Lougba & 14 & 2 & 6 & 1 & 5 & 3 & 2 & 14,29 \\
\hline 33 & Miniki & 14 & 4 & 3 & 0 & 7 & 2 & 5 & 35,71 \\
\hline 34 & Mougnon & 5 & 1 & 2 & 0 & 2 & 1 & 1 & 20 \\
\hline 35 & Ogoutèdo & 7 & 2 & 0 & 0 & 5 & 1 & 4 & 57,14 \\
\hline 36 & Okemere & 6 & 5 & 1 & 0 & 0 & 0 & 0 & 0 \\
\hline 37 & Oke-owo & 11 & 5 & 1 & 2 & 3 & 2 & 1 & 9,09 \\
\hline 38 & Okoutaossé & 14 & 3 & 1 & 1 & 9 & 3 & 6 & 42,86 \\
\hline 39 & Sowé & 11 & 1 & 3 & 0 & 7 & 3 & 3 & 36,36 \\
\hline 40 & Vedji & 10 & 4 & 1 & 0 & 5 & 1 & 4 & 40 \\
\hline \multirow[t]{2}{*}{41} & Yagbo & 8 & 4 & 0 & 1 & 3 & 0 & 0 & 37,50 \\
\hline & Moyenne & 10 & 3 & 2 & 1 & 4 & 1 & 3 & 42,22 \\
\hline
\end{tabular}

NTC : nombre total de cultivars; M+S+: beaucoup de ménages et grandes superficies; M+S-: beaucoup de ménages et petites superficies; M-S+: peu de ménage et grandes superficies ; M-S-: peu de ménages et petites superficies; CNI : cultivars nouvellement introduits ; NCD : nombre de cultivars en disparition ; TPC : taux de perte de cultivars. 
Tableau 4 : Variation de la diversité par Commune au centre Bénin.

\begin{tabular}{lcccc}
\hline Communes & $\begin{array}{c}\text { Nombre de } \\
\text { villages }\end{array}$ & $\begin{array}{c}\text { Nombre } \\
\text { Minimum de } \\
\text { cultivars }\end{array}$ & $\begin{array}{c}\text { Nombre } \\
\text { Maximum de } \\
\text { cultivars }\end{array}$ & $\begin{array}{c}\text { Diversité } \\
\text { Moyenne }\end{array}$ \\
\hline Bantè & 8 & 11 & 26 & $15 \pm 1,73 \mathrm{a}$ \\
Dassa & 8 & 3 & 11 & $8 \pm 0,94 \mathrm{~b}$ \\
Glazoué & 7 & 8 & 11 & $9 \pm 0,47 \mathrm{~b}$ \\
Savè - Ouèssè & 8 & 5 & 13 & $9 \pm 0,97 \mathrm{~b}$ \\
Savalou - Djidja & 10 & 5 & 14 & $10 \pm 1,34 \mathrm{bc}$ \\
\hline Zone d'étude & $\mathbf{4 1}$ & $\mathbf{3}$ & $\mathbf{2 6}$ & $\mathbf{1 0 \pm 0 , 7 4}$ \\
\hline
\end{tabular}

Les moyennes suivies de lettres différentes sont statiquement différentes

Tableau 5 : Nom vernaculaire, cycle, distribution et étendue de quelques cultivars élites du centre Bénin.

\begin{tabular}{|c|c|c|c|}
\hline $\mathbf{N}^{\mathbf{0}}$ & Nom vernaculaire & Cycle (mois) & Village, distribution et étendue \\
\hline 1 & Abidjan & 10 & Agao (++) ; Djagbalo (--) ; Idadjo (+-) \\
\hline 2 & Adjagun Nigéria & 10 & Ibiyem $(-+)$; Oke-owo $(++)$ \\
\hline 3 & Adoubiassi & 8 & Idadjo $(++)$ \\
\hline 4 & Ahôtonon & $7-12$ & $\begin{array}{c}\text { Abessouhoue (+-); Affizoungo (-+); Agao (++); } \\
\text { Betecoucou (--); Gnonkpingnon (++); Ibiyem (- -); } \\
\text { Okemere (++); Vedji (--); Yagbo }(++)\end{array}$ \\
\hline 5 & Ahôtonon fita & $7-12$ & Fita $(++)$ \\
\hline 6 & Atinwé & 18 & Abessouhoue $(++)$ \\
\hline 7 & Awoubi-èlou & 24 & Gbéré $(++)$ \\
\hline 8 & BEN & $7-12$ & $\begin{array}{l}\text { Affizoungo (--); Akatakou (-+); Akongbèré (-+) } \\
\text { Assaba }(++) \text {; Gobé }(-+) ; \text { Oke-owo }(++)\end{array}$ \\
\hline 9 & Blanwindji & 12 & Gbédé $(++)$ \\
\hline 10 & Carder rouge & 7 & $\begin{array}{c}\text { Agao (--); Akomiya (-+); Alafia (++); Attata } \\
(++) \text {; Betecoucou (-+); Ogoutèdo }(++) \text {; Sowe }(--) ; \\
\text { Vedji (--); Yagbo }(++)\end{array}$ \\
\hline 11 & Djabadjaba & 7 & Lama $(++)$ \\
\hline 12 & Dokouin & 24 & Agramidodji $(++) ;$ Lama $(--)$ \\
\hline 13 & Goro / Glotin & 24 & $\begin{array}{c}\text { Abessouhoue (+-); Fita (--); Gbedavo (++); } \\
\text { Gnonkpingnon (-+); Kouffota (--) ; Vedji (++) }\end{array}$ \\
\hline 14 & Idilèrou & 18 & $\begin{array}{c}\text { Akatakou (-+); Akomiya (--); Akongbèré (-+); } \\
\text { Assaba (--); Djagbalo (++); Gbédé (++) Gbéré } \\
(++) \text {; Ibiyem (-+); Okemere (++); Oke-owo (-+); } \\
\text { Sowe (- -) }\end{array}$ \\
\hline 15 & Israel & 6 & Idadjo (++) \\
\hline 16 & Lèlibo vovo & 7 & Gbedavo $(++)$ \\
\hline 17 & Lèlibo wéwé & 7 & Gbedavo $(++)$ \\
\hline 18 & Maboussa & $7-9$ & $\begin{array}{l}\text { Adja Pira (+-); Akatakou (+-); Assaba (++); Banon } \\
(++) \text {; Djagbalo (+-); Lougba (++); Okoutaossé }(++)\end{array}$ \\
\hline 19 & Malèbra & $12-18$ & $\begin{array}{c}\text { Kpakpavissa (- -); Akomiya (+ -); Betecoucou (+ -); } \\
\text { Banon (--); Ibiyem (- +); Oke-owo }(-+) \text {; Okemere } \\
(++) \text {; Sowe }(+-) \text {; Yagbo }(-+)\end{array}$ \\
\hline
\end{tabular}




\begin{tabular}{|c|c|c|c|}
\hline 20 & Martin & 8 & Idadjo $(++)$ \\
\hline 21 & Monlèkagan & 12 & Adja Pira (--) ; Assaba (++) \\
\hline 22 & Odohoungbo & $12-18$ & $\begin{array}{l}\text { Abessouhoué (++ ); Adjahossoudoxô1 (++); Adja } \\
\text { Pira (+-); Affizoungo (++); Agao (++); } \\
\text { Agramidodji (++); Akatakou(++); Akomiya (++); } \\
\text { Akongbèré (++); Alafia (++); Assaba (++); Attata } \\
\text { (++); Awamè (--) Banon (++); Djagbalo (++); } \\
\text { Djaloukou (++); Fita (++); Gbedavo (++); Gbédé } \\
(++) \text {; Gbéré (++); Gobé (++); Gnonkpingnon (+ } \\
\text { +); Gossoe (++); Ibiyem (++); Idadjo (++); } \\
\text { Kanahoun (++); Kafégnigbé (++); Kouffota (++); } \\
\text { Lougba (+ +); Miniki (+ +); Mougnon (++); } \\
\text { Okoutaossé (++); Okemere (++); Oke-owo (++); } \\
\text { Ogoutèdo (++); Sowe }(++) ; \text { Vedji (++); Yagbo } \\
(++)\end{array}$ \\
\hline 23 & Okôyawo doundoun & $7-9$ & $\begin{array}{l}\text { Adja Pira (+-); Akatakou(++); Assaba (++); Banon } \\
(++) \text {; Djagbalo (++); Kanahoun (+-); Kafégnigbé } \\
(++) \text {; Lougba }(+-) \text {; Miniki }(++) \text {; Okoutaossé }(++)\end{array}$ \\
\hline 24 & Oligbéssé & 18 & Okemere (++); Sowe (+-); Yagbo (--) \\
\hline 25 & $\mathrm{RB}$ & 12 & $\begin{array}{c}\text { Affizoungo (--); Akatakou(--); Assaba (++); } \\
\text { Kafégnigbé }(++) \text {; Kanahoun }(++)\end{array}$ \\
\hline 26 & Soukounon & 7 & Affezoungo $(++) ;$ Kouffota $(++)$ \\
\hline 27 & Sôwé & 7 & $\begin{array}{l}\text { Affizoungo (++); Fita (+ -); Gbedavo (++); } \\
\text { Gnonkpingnon (+-);Vedji (+-) }\end{array}$ \\
\hline 28 & Tms & 12 & $\begin{array}{l}\text { Affizoungo (--) ; Akatakou(++); Akongbèré (-+) ; } \\
\text { Assaba (++); Djagbalo (+-); Kanahoun (--) }\end{array}$ \\
\hline
\end{tabular}

Tableau 6 : Principales raisons de pertes de diversité variétale dans la région du centre Bénin.

\begin{tabular}{|c|c|c|}
\hline Catégories de raisons & Différents types & Pourcentage de réponses $(\%)$ \\
\hline \multirow{6}{*}{ Agronomiques $(\mathbf{8 9 , 8 0 \% )}$} & - Sensibilité à la sécheresse & 33,33 \\
\hline & $\begin{array}{l}\text { - Introduction de nouveaux } \\
\text { cultivars }\end{array}$ & 25,93 \\
\hline & $\begin{array}{l}\text { - Forte sensibilité } \quad \text { aux } \\
\text { maladies virales }\end{array}$ & 12,97 \\
\hline & - Cycle long & 10,18 \\
\hline & $\begin{array}{l}\text { - Desséchement rapide des } \\
\text { tiges }\end{array}$ & 4,62 \\
\hline & $\begin{array}{l}\text { - Inadaptabilité à la pauvreté } \\
\text { des sols }\end{array}$ & 2,77 \\
\hline \multirow[t]{2}{*}{$\begin{array}{l}\text { Culinaires et technologiques } \\
(\mathbf{1 0 , 2 0 \% )}\end{array}$} & $\begin{array}{l}\text { Toxicité des racines et des } \\
\text { feuilles }\end{array}$ & 5,60 \\
\hline & Mauvaise qualité de gari & 4,60 \\
\hline
\end{tabular}


A. P AGRE et al. / Int. J. Biol. Chem. Sci. 9(1): 388-408, 2015

Tableau 7: Caractéristiques des unités de manioc identifiées sur la base des identités agronomiques, culinaires et technologies.

\begin{tabular}{|c|c|c|c|c|c|c|c|c|c|c|c|c|c|}
\hline \multirow[t]{2}{*}{ Unit } & \multirow[t]{2}{*}{ NC } & \multirow[t]{2}{*}{ Composition } & \multicolumn{11}{|c|}{ Caractéristique agronomique, culinaire et technologique } \\
\hline & & & Pro & $\mathbf{C y}$ & CPT & Go & TF & RGa & QGa & TAm & QTa & QPa & RCI \\
\hline U1 & 1 & Abidjan & Fo & $\mathrm{Ta}$ & Bo & Do & $\mathrm{Fa}$ & Fo & Bo & Fo & Bo & Bo & $\mathrm{Se}$ \\
\hline $\mathbf{U 2}$ & 2 & Adoubiassi, Soukounon & Fo & $\operatorname{Pr}$ & Bo & Do & $\mathrm{Fa}$ & Fo & Bo & Fo & Bo & Bo & $\mathrm{Se}$ \\
\hline $\mathbf{U} 3$ & 3 & Adjagoun founfoun, RB, Cooco & Fo & $\operatorname{Pr}$ & Bo & Do & $\mathrm{El}$ & Fo & Bo & Fo & Bo & Bo & $\operatorname{Re}$ \\
\hline $\mathbf{U} 4$ & 3 & Adjagoun Nigeria, Atinwi, Baba Robert & Fo & $\operatorname{Pr}$ & Bo & Do & $\mathrm{Fa}$ & Fo & Bo & Fo & Bo & Bo & $\operatorname{Re}$ \\
\hline U5 & 5 & $\begin{array}{l}\text { Alexisfaingnin, Dalèfaingnin, Danandanan, Gohotô, } \\
\text { Kpassa }\end{array}$ & Fo & $\mathrm{Ta}$ & Bo & Do & $\mathrm{Fa}$ & Fo & Bo & Fo & Bo & Bo & $\operatorname{Re}$ \\
\hline U6 & 1 & Goro & $\mathrm{Fa}$ & $\mathrm{Ta}$ & Bo & Do & $\mathrm{Fa}$ & Fo & Bo & Fo & Bo & Bo & $\operatorname{Re}$ \\
\hline U7 & 1 & Hôlly & Fo & $\mathrm{Ta}$ & $\mathrm{Ma}$ & Do & $\mathrm{Fa}$ & Fo & Bo & Fo & Bo & Bo & $\operatorname{Re}$ \\
\hline U8 & 1 & Blanwidji & Fo & $\mathrm{Ta}$ & Bo & Do & $\mathrm{Fa}$ & Fo & Bo & $\mathrm{Fa}$ & Bo & Bo & $\mathrm{Re}$ \\
\hline U9 & 4 & $\begin{array}{l}\text { Maboussa, Martin, Okôiyawo doundoun, Okôiyawo } \\
\text { founfoun }\end{array}$ & $\mathrm{Fa}$ & $\operatorname{Pr}$ & Bo & Do & $\mathrm{Fa}$ & Fo & Bo & Fo & Bo & Bo & $\operatorname{Re}$ \\
\hline U10 & 1 & Tatawili & $\mathrm{Fa}$ & $\operatorname{Pr}$ & Bo & Do & $\mathrm{Fa}$ & Fo & Bo & $\mathrm{Fa}$ & Bo & Bo & $\operatorname{Re}$ \\
\hline U11 & 1 & Abohoungo & Fo & $\operatorname{Pr}$ & $\mathrm{Ma}$ & Am & $\mathrm{Fa}$ & Fo & Bo & Fo & Bo & Bo & $\operatorname{Re}$ \\
\hline $\mathbf{U 1 2}$ & 5 & BEN, Bioba, Fofovi, TMS , Ahotonon fita & Fo & $\operatorname{Pr}$ & $\mathrm{Ma}$ & Do & $\mathrm{Fa}$ & Fo & Bo & Fo & Bo & Bo & $\operatorname{Re}$ \\
\hline U13 & 2 & Carder blanc, Carder rouge & Fo & $\operatorname{Pr}$ & Ma & Do & $\mathrm{Fa}$ & Fo & Bo & $\mathrm{Fa}$ & Bo & Bo & $\operatorname{Re}$ \\
\hline U14 & 1 & Israel & Fo & $\operatorname{Pr}$ & $\mathrm{Ma}$ & Am & $\mathrm{Fa}$ & Fo & Bo & $\mathrm{Fa}$ & Bo & Bo & $\operatorname{Re}$ \\
\hline
\end{tabular}


A. P AGRE et al. / Int. J. Biol. Chem. Sci. 9(1): 388-408, 2015

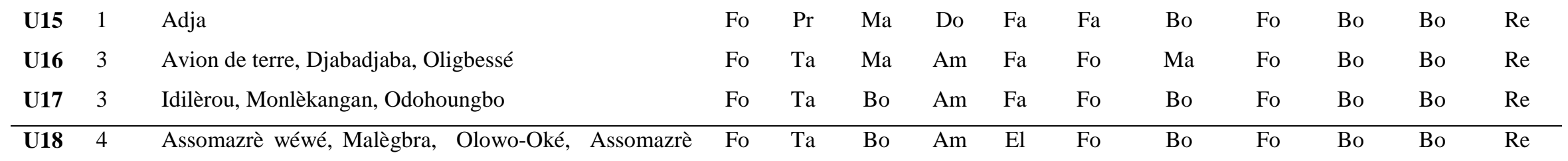
vovo

\begin{tabular}{|c|c|c|c|c|c|c|c|c|c|c|c|c|c|}
\hline U19 & 1 & Kpessimon & Fo & $\mathrm{Ta}$ & $\mathrm{Ma}$ & Do & $\mathrm{Fa}$ & $\mathrm{Fa}$ & Bo & $\mathrm{Fa}$ & Bo & Bo & $\operatorname{Re}$ \\
\hline $\mathbf{U} 20$ & 1 & Koukpabiékpo & Fo & $\mathrm{Ta}$ & Bo & Do & $\mathrm{Fa}$ & $\mathrm{Fa}$ & Bo & $\mathrm{Fa}$ & Bo & Bo & $\operatorname{Re}$ \\
\hline $\mathbf{U} 21$ & 1 & Ahossou faingnin & Fo & $\mathrm{Ta}$ & $\mathrm{Ma}$ & Do & $\mathrm{Fa}$ & Fo & Bo & Fo & Bo & Bo & $\mathrm{Se}$ \\
\hline $\mathbf{U} 22$ & 2 & Awoubièlou, Briguedé & Fo & $\mathrm{Ta}$ & $\mathrm{Ma}$ & Do & $\mathrm{El}$ & Fo & Bo & Fo & Bo & Bo & $\mathrm{Se}$ \\
\hline $\mathbf{U} 23$ & 2 & Atinwé, Houlamè Kloklo & Fo & $\mathrm{Ta}$ & $\mathrm{Ma}$ & Do & El & $\mathrm{Fa}$ & Bo & Fo & Bo & Bo & $\mathrm{Se}$ \\
\hline U24 & 2 & Ahôtônon, Bamsiigni & Fo & $\operatorname{Pr}$ & $\mathrm{Ma}$ & Am & El & Fo & Ma & Fo & Bo & Bo & $\operatorname{Re}$ \\
\hline U25 & 7 & $\begin{array}{l}\text { Dokouin, Lèlibô vovo, Lèlibô wéwé, Loki pétiole blanc, } \\
\text { Loki pétiole rouge Sowé, Houlamè guèguè }\end{array}$ & $\mathrm{Fa}$ & $\operatorname{Pr}$ & $\mathrm{Ma}$ & Do & $\mathrm{Fa}$ & $\mathrm{Fa}$ & Bo & $\mathrm{Fa}$ & Bo & $\mathrm{Ma}$ & $\mathrm{Se}$ \\
\hline
\end{tabular}

Pro: Productivité, Cy : Cycle, CPT: Conservation post maturité sous terre, Go: Goût, TF: Teneur en fibre, RGa: Rendement en gari, QGa: Qualité du gari, Tam: Teneur en amidon, QTa: Qualité du tapioca, QPa: Qualité de la pâte et RCI: Résistance des cossettes aux insectes de stockage. Fo: Fort(e), Pr: Précoce (6 à 10 mois), Ta: Tardif (supérieur à 10 mois), Ma: mauvaise, Do: Doux, Am: Amer, Fa: Faible, El: Elevé, Bo: Bonne, Re: Résistant et Se : Sensible. 
Tableau 8 : Critères de préférence paysanne et leur importance selon les groupes ethniques.

\begin{tabular}{|c|c|c|c|c|c|c|}
\hline \multirow{2}{*}{ Catégorie } & \multirow{2}{*}{ Critères } & \multirow{2}{*}{$\begin{array}{c}\text { Zone d'étude (\% } \\
\text { réponses) }\end{array}$} & \multicolumn{4}{|c|}{ Groupes ethniques (\% de réponses) } \\
\hline & & & Mahi/Fon & Idaatcha & Tachabè & Ifè \\
\hline \multirow{12}{*}{ Agronomiques } & Forte productivité & 16,37 & 12,66 & 11,93 & 16 & 24,88 \\
\hline & Précocité & 13,27 & 18,22 & 11,93 & 9,8 & 13,14 \\
\hline & Bonne conservation post-maturité sous terre & 8,01 & 7,58 & 5,50 & 8,9 & 10,05 \\
\hline & Tolérance à la sécheresse & 2,89 & - & 9,17 & 2,4 & - \\
\hline & Résistance aux maladies et ravageurs & 1,49 & 0,17 & 4,59 & 0,9 & 0,31 \\
\hline & Tolérance à l'excès d'humidité & 0,92 & - & 3,67 & - & - \\
\hline & Absence de fibres dans les racines & 0,87 & - & - & 3,5 & - \\
\hline & Facilité de récolte & 0,50 & 1,41 & - & 0,3 & 0,31 \\
\hline & Adaptabilité à tout type de sol & 0,37 & - & - & 1,3 & 0,18 \\
\hline & Tolérance aux mauvaises herbes & 0,037 & - & - & - & 0,15 \\
\hline & Tolérance aux sols pauvres & 0,19 & 0,78 & - & - & - \\
\hline & Total & 44,91 & 40,82 & 46,79 & 43,1 & 49,02 \\
\hline \multirow{10}{*}{ Culinaires et technologiques } & Bon rendement et qualité du gari & 15,52 & 19,88 & 10 & 20,6 & 11,59 \\
\hline & Aptitude de la racine au bon pilé & 9,53 & 12,89 & 6,42 & 8 & 10,82 \\
\hline & Aptitude à faire de bonnes cossettes & 6,54 & 12 & 7,04 & - & 7,11 \\
\hline & Qualité de la racine bouillie & 8,39 & 7,64 & 11,01 & 4,4 & 10,51 \\
\hline & Forte teneur en amidon et bonne qualité du tapioca & 5,17 & 3,89 & 11,01 & 3,8 & 2 \\
\hline & Feuilles utilisables comme légume & 2,58 & 1 & 7,73 & 1,6 & - \\
\hline & Bonne conservation des cossettes & 2,12 & - & - & 8,5 & - \\
\hline & Possibilité d'usages multiples & 1,74 & - & - & - & 6,95 \\
\hline & Facilité d'épluchage & 1,2 & - & - & 4,8 & - \\
\hline & Total & 52,79 & $\mathbf{5 7 , 3}$ & 53,21 & 51,7 & 48,98 \\
\hline Economiques & Forte valeur marchande & 2,27 & 1,88 & - & 5,2 & 2 \\
\hline
\end{tabular}




\section{DISCUSSION}

Dans la région centrale du Bénin, le manioc est une culture vivrière qui contribue fortement à la sécurité alimentaire et représente la principale source de revenus pour beaucoup de producteurs. On comprend pourquoi ces derniers ont cité l'autoconsommation et la commercialisation de produits dérivés comme leurs principales motivations dans la culture du manioc comme l'avait aussi signalé Hongbété et al. (2011). Malheureusement, la production du manioc est confrontée à plusieurs contraintes qui sont toutes directement ou indirectement d'ordre agronomique pouvant être levées par l'utilisation de cultivars performants. L'insuffisance de ceux-ci dans l'agriculture constitue d'ailleurs la contrainte la plus importante listée par les producteurs. Comme l'avait noté de nombreux auteurs (Aigbe et Remison 2010; Adjei-Nsiah, 2012; Kombo et al., 2012 ; Adriano et al., 2013) la recherche agronomique se doit de développer beaucoup de variétés performantes pour aider les producteurs à faire face aux effets néfastes des variabilités climatiques, aux maladies (surtout virose et Bactériose), aux ravageurs (cochenille et acariens) et à la pauvreté des sols qui entraînent selon Kombo et al. (2012) et Adriano et al. (2013) des pertes de production énormes. En attendant la création variétale et comme c'est le cas chez l'igname (Dansi et al., 2013 ; Loko et al., 2013), le niébé (Gbaguidi et al., 2013), le piment (Orobiyi et al., 2013) et le sorgho (DossouAminon et al., 2014) les quelques cultivars performants de manioc présents dans l'agriculture traditionnelle peuvent être identifiés et redéployés et les nombreux cultivars sélectionnés dans d'autres pays voisins (Côte d'ivoire, Ghana, Nigeria) par les institutions nationales ou internationales (IITA) peuvent être aussi introduits, testés et vulgarisés. La présente étude a conduit à juste titre à l'identification de cultivars élites qui ont d'ailleurs commencé à être exploités dans ce sens par les services de vulgarisation pour le bonheur des producteurs.
Sur la base des dénominations paysannes, 107 cultivars de manioc ont été recensés. Il est très peu probable que ceux-ci correspondent tous à des clones différents. Dans la nomenclature vernaculaire de variétés de plantes cultivées, les noms vernaculaires varient généralement d'une ethnie à une autre, d'un village à un autre au sein de la même zone ethnique et parfois d'un ménage à un autre au sein d'un même village (Dansi et al., 2010 ; Kombo et al., 2010 ; Loko et al., 2013). Dans ce contexte, un même cultivar à travers les villages peut être désigné par différents noms et des cultivars différents peuvent parfois être désignées par la même appellation (Tamiru et al., 2008 ; Otoo et al., 2009). Pour éviter une surestimation ou une sousestimation de la diversité variétale et faciliter l'utilisation efficiente des cultivars locaux, ceux-ci doivent être collectés et caractérisés aussi bien sur la base des marqueurs morphologiques que moléculaires (Lekka et al., 2011 ; Kombo et al., 2012).

Bien que la diversité variétale apparaît importante à travers la zone d'étude, elle se révèle très faible par rapport à celle retrouvée dans les villages amérindiens (Elias et al., 2001 ; da Costa et al., 2013). En fait, les producteurs de cette zone (centre d'origine du manioc) exploitent les plantules issues des graines pour renforcer la diversité de leur matériel végétale (Elias et al., 2001; Peroni et al., 2007). La multiplication par les graines qui constitue une source de nouveaux génotypes (Rival et al., 2008) est malheureusement peu connue des producteurs du centre Bénin. La mise en place de programme de sélection participative décentralisée est indispensable et permettra aux producteurs de manioc d'augmenter la diversité variétale à travers les semis des graines (issues de croisements libres ou orientés) et l'entretien des plantules issues de graines qui poussent naturellement dans les champs.

La distribution et l'étendue des cultivars de manioc varient d'un village à l'autre. Du point de vue de la conservation des ressources 
génétiques, les cultivars cultivés par beaucoup de ménages sur de grandes superficies ne sont pas menacés et peuvent simplement faire l'objet d'une conservation in situ (Jarvis et al., 2000 ; Dansi et al., 2010). Par contre ceux cultivés par peu de ménages sur de petites superficies méritent une attention particulière sur le plan de la conservation. Il serait important de les collecter et de les préserver ex situ (surtout in vitro). Pour les autres cultivars des cadrants intermediaires (peu de menages et grandes superficies; beaucoup de menages et peu de superficies) et suivant Jarvis et al. (2000) l'approche complementaire (in situ et ex situ) sera necessaire. Comme chez l'igname au Bénin (Loko et al., 2013) et le manioc au Congo (Kombo et al., 2012), le taux moyen de perte de diversité observé dans la zone est rélativent elevé $(42,22 \%)$ et indique la necessité d'actions urgentes. Les taux nul observés dans certains villages ne signifient pas une meilleure conservation mais plutôt que le seuil maximum d'abandon de cultivars est atteint. Des résultats similaires ont été observés sur le fonio (Dansi et al., 2010), l'igname (Dansi et al., 2013; Loko et al., 2013), le niébé (Gbaguidi et al., 2013) et le piment (Orobiyi et al., 2013).

Vingt et un (21) critères sous-tendent la préférence ou le choix des cultivars de manioc dans cette zone d'étude. Ces critères sont non seulement liés à des caractéristiques intrinsèques des cultivars, mais aussi à des facteurs liés aux contraintes (biotiques et abiotiques) de production et de commercialisation (Ojulong et al., 2010; Kombo et al., 2012). Parmi ces critères, la forte productivité (racines longues et grosses), la précocité des cultivars sont les plus importants. Ces résultats sont en accord avec ceux de Teshome et al. (2007) sur le sorgho, Ojulong et al. (2010) et Kombo et al. (2012) sur le manioc et Dansi et al. (2013) sur l'igname qui ont montré que ces critères d'importance économique sont les plus recherchés par les sélectionneurs et pour toutes les cultures. La variabilité des critères de préférence entre zones ethniques déjà été observée sur le fonio (Adoukonou et al., 2006), les légumes feuilles (Dansi et al., 2008), le sorgho (Dossou-Aminon et al., 2014) et même le manioc (Kombo et al., 2012) guidera les programmes de sélection et orientera les échanges variétaux. La précocité est ici un critère de préférence important. $\mathrm{Ce}$ résultat n'est pas surprenant lorsqu'on se réfère aux variabilités climatiques déjà très perceptibles au centre Bénin (Loko et al., 2013). Les variétés précoces confèreront aux producteurs la garantie qu'avant les coupures précoces de pluie maintenant trop fréquentes, un niveau significatif de production serait déjà atteint et une récolte sera possible pour la satisfaction des besoins alimentaires et économiques.

\section{Conclusion}

Cette étude effectuée au Centre Bénin sur les contraintes de production, la diversité et les critères paysans de préférence a révélé que la production du manioc est confrontée à plusieurs contraintes biologiques qui peuvent être surmontées par l'utilisation de cultivars adaptés, performants déjà existants ou à créer. La diversité variétale révélée est indicatrice de possibilité de succès des programmes de sélection. Cependant, il faudra la collecter, la caractériser (caractérisation morphologique et moléculaire), la préserver (aussi bien par l'approche ex situ que par la conservation in situ à la ferme) et la renforcer à travers les sélections participatives intégrant l'exploitation de la reproduction sexuée.

\section{REMERCIEMENTS}

Cette étude a été réalisée dans le cadre $\mathrm{du}$ projet PAES (Programme d'Appui à l'Enseignement Supérieur) financé entièrement par l'UEMOA (Union Economique et Monétaire Ouest Africaine). Nous remercions $\mathrm{Mr}$ Philippe AKODJI (technicien à BORAVE, FAST Dassa) pour son appui technique et les producteurs du manioc du Centre Bénin ainsi que les chefs des villages visités pour leurs franches collaborations. 


\section{REFERENCES}

Adjei-Nsiah S. 2012. Evaluating sustainable cropping sequences with cassava and three grain legume crops: Effects on soil fertility and maize yields in the semideciduous forest zone of Ghana. Journal of Soil Science and Environmental Management, 3(2): 49-55.

Adomou AC, Sinsin B, Van der Maesen LJG. 2006. Phytosociological and chorological approaches to Phytogeography: A study at meso-scale in Benin. Systematics and Geography of Plants, 2(76): 155-178.

Adoukonou-Sagbadja H, Dansi A, Vodouhè R, Akpamagan K. 2006. Indigenous

knowledje and traditional conservation of fonio millet (Digitaria exillis Stapf, Digitaria iburua Stapf) in Togo. Biodiversity and Conservation, 15: 2379-2395.

Adriano SR, Adenir VT, Anilde GS, Renato AS. 2013. Relative contribution of biotic and abiotic factors to the population density of the cassava green mite, Mononychellus tanajoa (Acari: Tetranychidae). Experimental and Applied Acarology, 276:1496-1505.

Agre AP, Dansi A, Rabbi IY, Battachargee R, Dansi M, Melaku G, Augusto B, Sanni A, Akouegninou A, Akpagana K. 2015. Agromorphological Characterization of Elite Cassava (Manihot esculenta Crantz) Cultivars Collected in Benin. Int. J. Curr. Res. Biosci. Plant Biol., 2(2): 1-14.

Aigbe S, Remison SU. 2010. The influence of growth stages on cassava tuberous root rot in different ecological environments. Phytopathology and Plant Protection, 43(12): 1243-1248.

Cacaï G, Ahanhanzo C, Adjanohoun A, Houédjissin S, Azokpota P, Agbangla C. 2013. Hormonal influence on the in vitro bud burst of some cassava varieties and accessions from Benin. African Journal of Biotechnology, 12(13): 14751481.
Carinne NMC, Brígida ABS, Borges BN, Neto MAM, Carvalho LB, de Souza CB. 2011. Levels of MeLEA3, a cDNA Sequence Coding for an Atypical Late Embryogenesis Abundant Protein in Cassava, Increase Under In Vitro Salt Stress Treatment. Plant Molecular Biology, 52(4): 997-1005.

Chiara C, Serpagli MA. 2009. Benin : Etude sur la Commercialisation des Produits Dérivés du Manioc Vers les Marchés des Pays Limitrophes (Niger, Nigeria, Togo et Burkina Faso). IFAD : Cotonou, Benin.

da Costa TR, Pedro Soares VF, Maria C, Marta ZG, Giselly FL, da Silva LI, Marcus VK. 2013. Genetic diversity and population structure of sweet Cassava Using Simple Sequence repeat (SSR) molecular marker. African Journal of Biotechnology, 12(10): 10401048.

Dansi A, Adjatin A, Adoukonou Sagbadja H, Faladé V, Yedomonhan $\mathrm{H}$, Odou D, Dossou B. 2008. Traditional leafy vegetables and their use in the Benin Republic. Genetic Resources and Crop Evolution, 55(8): 1239-1256.

Dansi A, Adoukonou-Sagbadja $\mathrm{H}$, Vodouhè R. 2010. Diversity, conservation and related wild species of Fonio millet (Digitaria spp) in the northwest of Benin. Genetic. Resources and crop Evolution, 57(6): 827-839.

Dansi A, Dantsey-Barry H, Agre AP, DossouAminon I, Assogba P, Loko YL, N'Kpenu EK, Kombaté K, Dansi M, Vodouhè R. 2013. Production constraints and farmers' cultivar preference criteria of cultivated yams (Dioscorea cayenensis - D. rotundata complex) in Togo. International Journal of Applied Biology and Pharmaceutical Technology, 4(2): 191-199.

Dossou-Aminon I, Loko LY, Adjatin A, Dansi A, Elangovan M, Chaudhary P, Vodouhè R, Sanni A. 2014. Diversity, genetic erosion and farmers' preference 
of sorghum varieties [Sorghum bicolor (L.) Moench] in North-Eastern Benin. Int. J. Curr. Microbiol. App. Sci., 3(10): 531-552.

Elias M, Rival L, Mckey D. 2001. Perception and management of cassava (manihot esculenta Crantz) diversity among Makushi Amerindiang of Guyana (South America). Journal of Ethnobiology, 20(2): 239-265.

Esuma W, Patrick R, Anthony P, Robert K, Bramwel W. 2012. Genetic Diversity of Provitamin A Cassava in Uganda. Journal of Plant Studies, 1(1): 60-70.

FAO 2013. FAOSTAT Database. Food and Agriculture Organization, Roma, Italy. Available online at URL: www.fao.org.

Gbaguidi AA, Dansi A, Loko LY, Dansi M, Sanni A. 2013. Diversity and agronomic performances of the cowpea (Vigna unguiculata Walp.) landraces in Southern Benin. International Research Journal of Agricultural Science and Soil Science, 3(4): 121-133.

Guerrero EL, Narayanan N, Ihemere U, Richard TS. 2012. Iron and protein biofortification of cassava: lessons learned. Food Biotechnology, 23(2): 257-26.

Hongbété F, Mestres C, Akissoé N, Pons B, Hounhouigan D, Cornet D, Nago CM. 2011. Effects of cultivar and harvesting conditions (age, season) on the texture and taste of boiled cassava roots. Food Chemistry, 126(1): 127-133.

Jarvis D, Myer L, Klemick H, Guarino L, Smale M, Brown AHD, Sadiki M, Sthapit B, Hodgkin T. 2000. A Training Guide for In situ Conservation On-Farm (Version 1). Rome, Italie.

Kombo GR, Dansi A, Loko LY, Orkwor GC, Vodouhè R, Assogba P, Magema JM. 2012. Diversity of cassava (Manihot esculenta Crantz) cultivars and its management in the department of Bouenza in the Republic of Congo. Genetic Resources and Crop Evolution, 59(8): 1789-1803.
Kumba K. 2012. Genetic characterization of exotic and landraces of cassava in Ghana. M.Sc., in Agronomy, Kwamenkrumah University of Science and Technology, 111p.

Loko YL, Dansi A, Linsoussi C, Tamo M, Vodouhè R, Akoegninou A, Sanni A. 2013. Current status and spatial analysis of Guinea yam (Dioscorea cayenensis Lam. $-D$. rotundata Poir. complex) diversity in Benin. International Research Journal of Agricultural Science and Soil Science, 3(7): 219-238.

MAEP (Ministère de l'Agriculture de l'Elevage et de la Pêche). 2013. Evolution de réalisations des principales cultures par commune (Période: 19982010), MAEP.

Ojulong HF, Labuschagne MT, Herselman L, Fregene M. 2010. Yield traits as selection indices in seedling populations of cassava. Crop Breeding Apply Biotechnology, 10(3): 14-26.

Onzo A, Hanna R, Sabeli MW, Yaninek JS. 2005. Temporal and Spatial Dynamics of an Exotic Predatory Mite and Its Herbivorous Mite Prey on Cassava in Benin, West Africa. Environmental Entomology, 34(4): 866-874.

Orobiyi A, Dansi A, Assogba P, Loko LY, Dansi M, Vodouhè R, Akouègninou A, Sanni A. 2013. Chili (Capsicum annuum L.) in southern Benin: production constraints, varietal diversity, preference criteria and participatory evaluation. International Research Journal of Agricultural Science and Soil Science, 3(4): 107-120.

Otoo E, Akromah R, Kololesnikova-Allen M, Asiedu R. 2009. Ethno-botany and morphological characterisation of the yam pona complex in Ghana. African Crop Science, 9: 407-414.

Peroni N, Kageyama PY, Begossi A. 2007. Molecular differentiation, diversity and folk classification of sweet and bitter cassava (Manihot esculenta) in Caicara and Caboclo management systems in 
Brazil. Genetic Resources and Crop Evolution, 54(2): 1249-1333.

Rival L, Mckey D. 2008. Domestiction and diversity in Cassava (Manihot esculenta Crantz, Euphorbiaceae). Current Anthropologie, 9: 1119-1128.

Shannon CE, Weaver W. 1948. A mathematical theory of communication. Bell System Technical Journal, 27: 379423.

Tamiru M, Becker CH, Maas BL. 2008. Diversity, distribution and management of yam landraces (Dioscorea spp.) in Southern Ethiopia. Genetic Resources and Crop Evololution, 55: 115-131.
Teshome A, Patterson D, Asfew Z, Torrance JK, Arnason JT. 2007. Changes of Sorghum bicolor landrace diversity and farmers' selection criteria over space and time, Ethiopia. Genetic Resources and Crop Evololution., 54(6): 12191233.

Turyagyenda L, Kizito EB, Ferguson M, Baguma Y, Agaba M, Harvey JW, David SO. 2013. Physiological and molecular characterization of drought responses and identification of candidate tolerance genes in cassava. African Crop Science Journal, 20(1): 15-30. 